\title{
Chemical growth of hexagonal zinc oxide nanorods and their optical properties
}

\author{
Pijus Kanti Samanta $\cdot$ Ashok Kumar Bandyopadhyay
}

Received: 25 July 2011/Accepted: 25 September 2011/Published online: 22 November 2011

(C) The Author(s) 2011. This article is published with open access at Springerlink.com

\begin{abstract}
A simple wet chemical method has been successfully deployed to fabricate hexagonal zinc oxide nanorods. The structural characteristics were investigated through X-ray diffraction. The crystal unit cell of the nanorods was found to be hexagonal. The morphology of the nanostructures was studied using field emission scanning electron microscopy and transmission electron microscopy. The nanorods are hexagonal in shape. The $\mathrm{Zn}-\mathrm{O}$ bond formation was confirmed through Fourier transformed infrared spectroscopic analysis. Raman shift measurements revealed various vibrational modes present in the $\mathrm{ZnO}$ crystal. The photoluminescence spectrum shows shallow deep level visible emission due to various defect states. Thus, our investigation will be very helpful in the development of $\mathrm{ZnO}$ based light emitting/optoelectronic device applications.
\end{abstract}

Keywords Zinc oxide $\cdot$ Nanorods $\cdot \mathrm{Zn}-\mathrm{O}$ bond $\cdot$ Ramanshift $\cdot$ Photoluminescence $\cdot$ Visible-emission $\cdot$ Defect-states

\section{Introduction}

Zinc oxide $(\mathrm{ZnO})$ is a very well known II-IV semiconductor having interesting unique properties that lead to its applications in sensors, optoelectronic, and nanoelectronic devices (Wang et al. 2006; Song et al. 2010; Umar et al. 2009a, b; Rout et al. 2009). Due to its wide band gap of $3.37 \mathrm{eV}$ and large exciton binding energy of $60 \mathrm{meV}$ (Wang et al. 2009a), it exhibits stable UV emission (Duan

P. K. Samanta $(\bowtie) \cdot$ A. K. Bandyopadhyay

Department of Physics, Ghatal Rabindra Satabarsiki

Mahavidyalaya, Ghatal, Paschim Medinipur,

Ghatal 721212, West Bengal, India

e-mail: pijush.samanta@gmail.com et al. 2006). Researchers reported that visible emission from the $\mathrm{ZnO}$ nanostructures originates because of the existence of various defects ( $\mathrm{Zn}$ interstitial, $\mathrm{Zn}$ vacancy, and oxygen vacancy) in the $\mathrm{ZnO}$ nanocrystal (Nian et al. 2010; Wang et al. 2009b; Patra et al. 2009). These emissions make $\mathrm{ZnO}$, a very interesting material for various optoelectronic applications. $\mathrm{ZnO}$ is now being used as UV absorbing material in sunscreens (Schilling et al. 2010), transparent conductors in solar cells (Lloyd et al. 2009), and nano-lasers (Zhang et al. 2009). Recently Wang (2008) has successfully demonstrated energy generation from arrayed $\mathrm{ZnO}$ nanorods using the piezo-electric property exhibited by this material. In addition to these optoelectronic and nanoelectronic device applications, $\mathrm{ZnO}$ is also being used in spintronic applications. Existence of ferromagnetism in $\mathrm{ZnO}$ was already shown by Iqbal et al. (2009). The idea of this ferromagnetism is now being used in magnetic non-volatile data storage for longer periods of time. Thus, $\mathrm{ZnO}$ offers us a possibility to combine the optical and magnetic property in various advanced devices like spin light-emitting-diodes, spin-polarized solar cells, and magneto-optical switching.

In this paper, we report the fabrication of hexagonal $\mathrm{ZnO}$ nanorods by a simple and cost-effective wet chemical method. Moreover, it offers us repeated fabrication of pure $\mathrm{ZnO}$. The fabrication is followed by few typical characterization results that are very interesting and useful in $\mathrm{ZnO}$ base optoelectronic and nanoelectronic device applications.

\section{Experimental}

Material preparation

The chemicals used in the fabrication of $\mathrm{ZnO}$ nanorods, were of analytical grade and was used as supplied

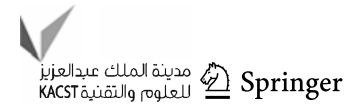


(MERCK) without further purification. $14.87 \mathrm{~g}$ of zinc nitrate hexahydrate $\left(\mathrm{Zn}\left(\mathrm{NO}_{3}\right)_{2} \cdot 6 \mathrm{H}_{2} \mathrm{O}\right)$ was dissolved in deionized water to prepare $100 \mathrm{ml}$ solution of concentration 0.5 M. $4 \mathrm{~g}$ of sodium hydroxide $(\mathrm{NaOH})$ was dissolved in deionized water to prepare $100 \mathrm{ml} \mathrm{NaOH}$ solution of concentration $1 \mathrm{M}$. This $\mathrm{NaOH}$ solution was then put under vigorous stirring at room temperature $\left(34^{\circ} \mathrm{C}\right)$ in a conical flask using a magnetic stirrer (SPINOT make). The previously prepared zinc nitrate solution of $0.5 \mathrm{M}$ was added drop-wise to the $\mathrm{NaOH}$ solution for $15 \mathrm{~min}$. The mechanical stirring was continued for $2 \mathrm{~h}$. The $\mathrm{pH}$ of the solution was 11. A white precipitate was deposited at the bottom of the flask. The precipitate was then filtered and washed 2-3 times with distilled water. Then the powdered sample was dried and annealed at different temperatures (200, 400, and $800^{\circ} \mathrm{C}$ ) in a furnace for further characterizations.

\section{Material characterization}

The X-ray diffraction (XRD) data were collected in a RIGAKU diffractometer using $\mathrm{Cu} \mathrm{K}_{\alpha}$-radiation over an angular range $30^{\circ}<2 \theta<60^{\circ}$ by an ionization chamber. The morphology of the samples were observed using ZEISS SUPRA-40 field emission scanning electron microscope (FESEM) operating at $5 \mathrm{kV}$ accelerating voltage and the working distance between the samples and the detector was $\sim 1.5 \mathrm{~cm}$. Transmission electron microscopy (TEM) was carried out in a JEOL JEM-2100F microscope with the accelerating voltage of $200 \mathrm{kV}$. For TEM study, a very small amount of the powder sample was first dispersed in acetone by ultrasonication. A drop of that solution was taken on a carbon coated grid and dried in vacuum for TEM imaging. Fourier transformed infra-red spectroscopy (FTIR) was carried out in NEXUS-870 FT-IR spectrometer. Reinshaw Raman system: RM-1000B (coupled with LEICA microscope DMLM) was deployed to carry out the Raman shift measurement of the $\mathrm{ZnO}$ nanorods. As the excitation source, a $20 \mathrm{~mW}$ Argon ion laser was used which was operated at $514 \mathrm{~nm}$ wavelength using an edge filter of $200 \mathrm{~cm}^{-1}$ as cut-off. The optical emission characteristic of the $\mathrm{ZnO}$ nanorods was analysed by recording the photoluminescence (PL) spectrum at room temperature using PERKIN ELMER LS-55 luminescence spectrometer with a xenon lamp at the excitation of $325 \mathrm{~nm}$.

\section{Results and discussions}

$\mathrm{X}$-ray diffraction $(\mathrm{XRD})$

A typical XRD pattern of the $\mathrm{ZnO}$ nanorods annealed at $400^{\circ} \mathrm{C}$ is shown in Fig. 1. The unit cell of the crystal was found to be hexagonal with the presence of the peaks (100),

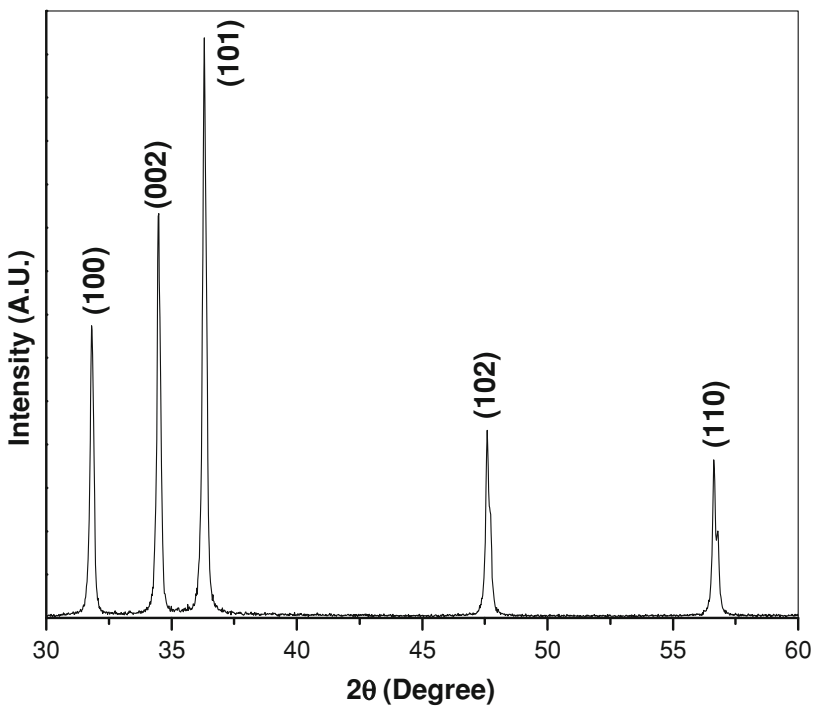

Fig. 1 XRD pattern of $\mathrm{ZnO}$ nanorods annealed at $400^{\circ} \mathrm{C}$

(002), (101), (102), and (110). It is well agreed with the standard JCPDS card no. 36-1451. Furthermore, the intensities of different diffraction peaks are different, which indicates that the growth of various planes (direction) is different and that the growth is anisotropic. The crystallite size was calculated using the well known Scherer formula (Samanta and Chaudhuri 2011): $R_{\mathrm{hkl}}=\frac{0.89 \lambda}{\beta \cos \theta}$. In this calculation, the highest intensity (101) peak was analysed and considered it to be Gaussian. The crystallite size was found to be $43 \mathrm{~nm}$. Besides, no impurity peaks were detected which indicates that the fabricated $\mathrm{ZnO}$ nanomaterials is highly pure.

Growth and morphology of the nanostructures

Typical FESEM image of the as prepared $\mathrm{ZnO}$ nanorods is shown in Fig. 2a. Rod-like nanostructures were clearly observed. The nanorods are randomly distributed in the powdered sample. The length of the nanorods is $\sim 400 \mathrm{~nm}$ and diameter is $\sim 100 \mathrm{~nm}$. Growth of various $\mathrm{ZnO}$ nanostructures from aqueous solution (containing $\mathrm{Zn}(\mathrm{OH})_{4}^{2-}$ ) has been reported by many researchers. However, the growth process and mechanism of the formation of $\mathrm{ZnO}$ from $\mathrm{Zn}(\mathrm{OH})_{4}^{2-}$ is not yet well understood. The reported mechanism of formation of $\mathrm{ZnO}$ by researchers ( $\mathrm{Li}$ et al. 2007; Kale et al. 2007; Hu et al. 2007; Quang et al. 2005; Shan et al. 2004; Zhang et al. 2002; Wu et al. 2006; Samanta et al. 2009a) is as follows:

$\mathrm{Zn}^{2+}+2 \mathrm{OH}^{-} \rightarrow \mathrm{Zn}(\mathrm{OH})_{2} \downarrow$

$\mathrm{Zn}(\mathrm{OH})_{2}+2 \mathrm{OH}^{-} \rightarrow \mathrm{Zn}(\mathrm{OH})_{4}^{2-}$

$\mathrm{Zn}(\mathrm{OH})_{4}^{2-} \rightarrow \mathrm{ZnO}+2 \mathrm{H}_{2} \mathrm{O}+2 \mathrm{OH}^{-}$

We depict the formation mechanism of $\mathrm{ZnO}$ nanorods in two steps: nucleation and growth. At the initial step of the 

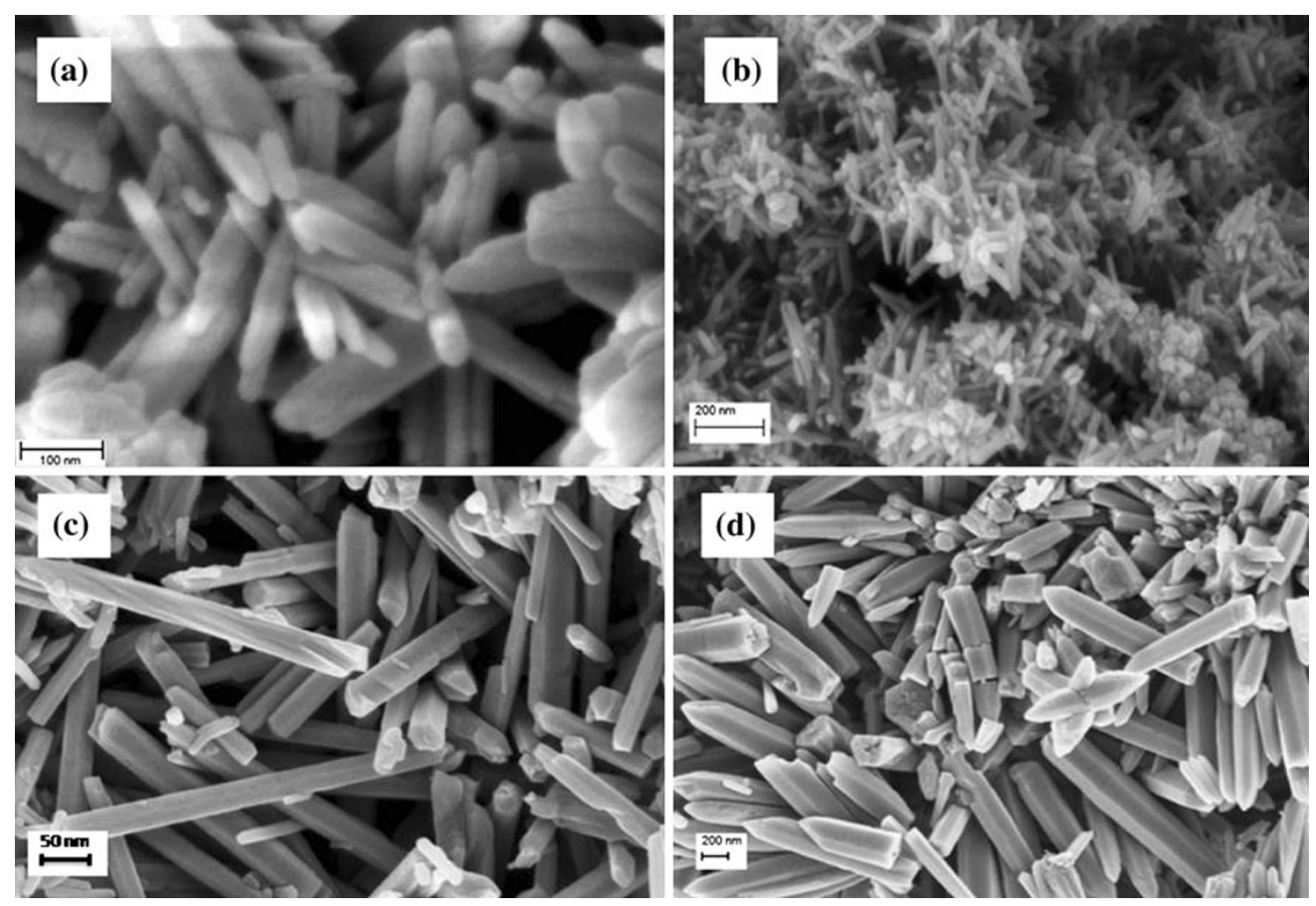

Fig. 2 FESEM images of the a as synthesized $\mathrm{ZnO}$ nanorods, and $\mathrm{ZnO}$ nanorods annealed at $\mathbf{b} 200^{\circ} \mathrm{C}$, c $400^{\circ} \mathrm{C}$, and $\mathbf{d} 800^{\circ} \mathrm{C}$, respectively

reaction between $\mathrm{Zn}\left(\mathrm{OH}_{3}\right)_{2}$ and $\mathrm{NaOH}, \mathrm{Zn}(\mathrm{OH})_{2}$ precipitates. Now as more $\mathrm{NaOH}$ is added to the solution, the precipitated $\mathrm{Zn}(\mathrm{OH})_{2}$ dissolves and forms a homogeneous aqueous solution that contains enough $\mathrm{Zn}(\mathrm{OH})_{4}^{2-}$ ions. At the onset of supersaturation and dehydration of $\mathrm{Zn}(\mathrm{OH})_{4}^{2-}$ $\mathrm{ZnO}$ nuclei are formed. It is also supposed that during this process, $\mathrm{Zn}(\mathrm{OH})_{4}^{2-}$ ions act as the growth unit of $\mathrm{ZnO}$ and directly incorporated into $\mathrm{ZnO}$ crystallites. These nuclei grow further to produce rod-like $\mathrm{ZnO}$. However, there are also some other equilibrium processes $\left(\mathrm{ZnO}-\mathrm{H}_{2} \mathrm{O}\right)$ for the formation of $\mathrm{ZnO}$ as reported by Quang et al. (2005). But these needs further investigations.

$\mathrm{Zn}^{2+}+\mathrm{H}_{2} \mathrm{O} \leftrightarrow \mathrm{ZnO}+2 \mathrm{H}^{+}$

$\mathrm{ZnOH}^{+} \leftrightarrow \mathrm{ZnO}+\mathrm{H}^{+}$

$\mathrm{Zn}(\mathrm{OH})_{2} \leftrightarrow \mathrm{ZnO}+\mathrm{H}_{2} \mathrm{O}$

$\mathrm{Zn}(\mathrm{OH})_{3}^{-}+\mathrm{H}^{+} \leftrightarrow \mathrm{ZnO}+2 \mathrm{H}_{2} \mathrm{O}$

$\mathrm{Zn}(\mathrm{OH})_{4}^{2-}+2 \mathrm{H}^{+} \leftrightarrow \mathrm{ZnO}+3 \mathrm{H}_{2} \mathrm{O}$

The wurtzite structure of $\mathrm{ZnO}$ can be described as a stack of a number of alternating planes that are fourfold co-ordinated $\mathrm{O}^{2-}$ and $\mathrm{Zn}^{2+}$ ions arranged along $c$-axis. Several crystal planes exist: the basal plane (0001), one end of this plane is terminated to $\mathrm{Zn}$ lattice points and $(000 \overline{1})$ plane terminates to negative oxygen lattice points (Sugunan et al. 2006). The other six low index non-polar facets (1010) are parallel to $c$-axis. The non-polar facets are energetically most stable and the polar facets are metastable (Pan et al. 2001). The growth rate of various planes follows the growth rule: $V(0001)>V(01 \overline{1} \overline{1})>$ $V(01 \overline{1} 0)>V(01 \overline{1} 1)>V(000 \overline{1})(\mathrm{Li}$ et al. 1999). Now the growth rate of (0001) plane is very high. As a result it will be disappeared quickly. Thus, this plane disappears in the experimentally synthesized $\mathrm{ZnO}$ leading to the rod-like structure (Li et al. 1999). A more detailed understanding of the growth rate dependence of various morphologies of $\mathrm{ZnO}$ nanostructures is reported by Li et al. (1999). Schematic of the growth of the nanorods is shown in Fig. 3. On annealing the nanorods at higher temperatures, the small crystallites coalesce together to form large crystallites and the crystallinity of the material improves, and hence defect states are reduced. Hence shape evolution occurs. There are possibilities of hydroxide shell surrounding the as-synthesized nanorods. But high temperature annealing will remove these hydroxide shell layers. As a result wellgrown hexagonal nanorods with narrow tips were observed as shown in Fig. 2b-d).

Transmission electron microscopy (TEM) study

Typical TEM image of the nanorods annealed at $400^{\circ} \mathrm{C}$ is shown in Fig. 4a, b. We observed rod-like structures with diameter $\sim 50-100 \mathrm{~nm}$ and length $\sim 400 \mathrm{~nm}$ as measured 

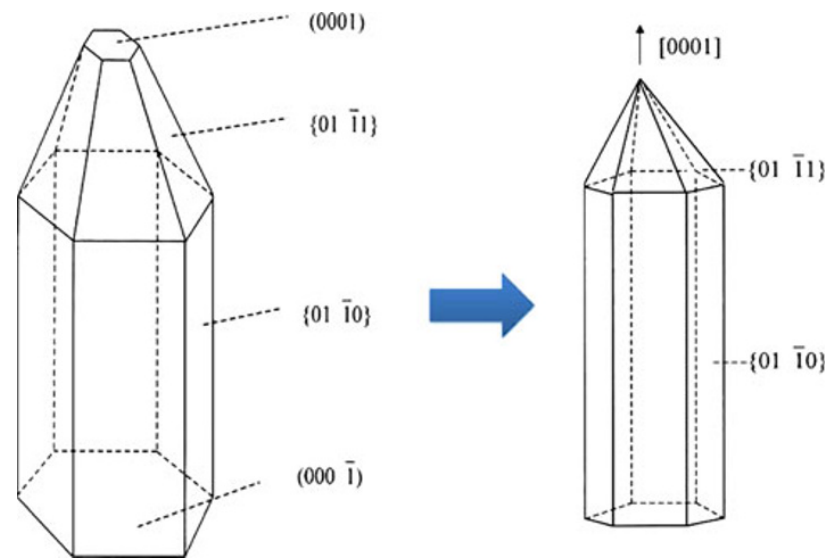

Fig. 3 Schematic of the growth of the nanorods [reproduced with permission from 27]

from TEM image. The crystallite size $(43 \mathrm{~nm})$ is less than the diameter of the nanorods, which indicates the nanorods are composed of several crystallites. The selected area electron diffraction (SAED) pattern is also shown in the inset of Fig. 4b. The linear diffraction points indicate that the diffraction occurs from a single crystallite within the nanorods.

Fourier transformed infra-red spectroscopy

Figure 5 shows the FTIR spectrum of the $\mathrm{ZnO}$ nanorods. A very strong band is observed at $\sim 500 \mathrm{~cm}^{-1}$. This is assigned to the $\mathrm{Zn}-\mathrm{O}$ stretching bonds (Faal Hamedani and Farzaneh 2006). Another peak at $1,625 \mathrm{~cm}^{-1}$ arises due to the $\mathrm{O}-\mathrm{H}$ bending mode of water. The vibration mode of $\mathrm{OH}$ group was also observed at $3,429 \mathrm{~cm}^{-1}$. It revealed

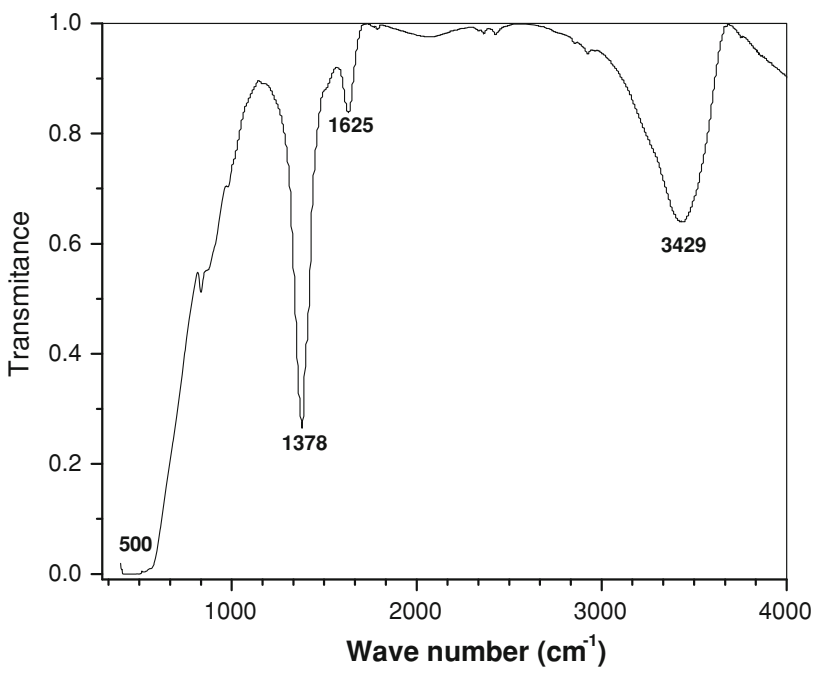

Fig. 5 FTIR spectrum of the $\mathrm{ZnO}$ nanorods showing the absorption for various bonds

that some water was absorbed by the sample from the atmosphere. The peak at $1,378 \mathrm{~cm}^{-1}$ appeared due to symmetric stretching mode of $\mathrm{N}=\mathrm{O}$ coming from some unreacted zinc nitrate.

\section{Raman shift measurement}

Chemical growth of nanostructured materials usually involves the formation of large amount of surface defects in the nanocrystals. Thus, the Raman spectra of these chemically grown nanomaterials are red shifted and broadened due to the relaxation of the selection rule for the $q$-vector (conservation of crystal momentum) within the finite size of the nanocrystals. Also the phonon scattering in
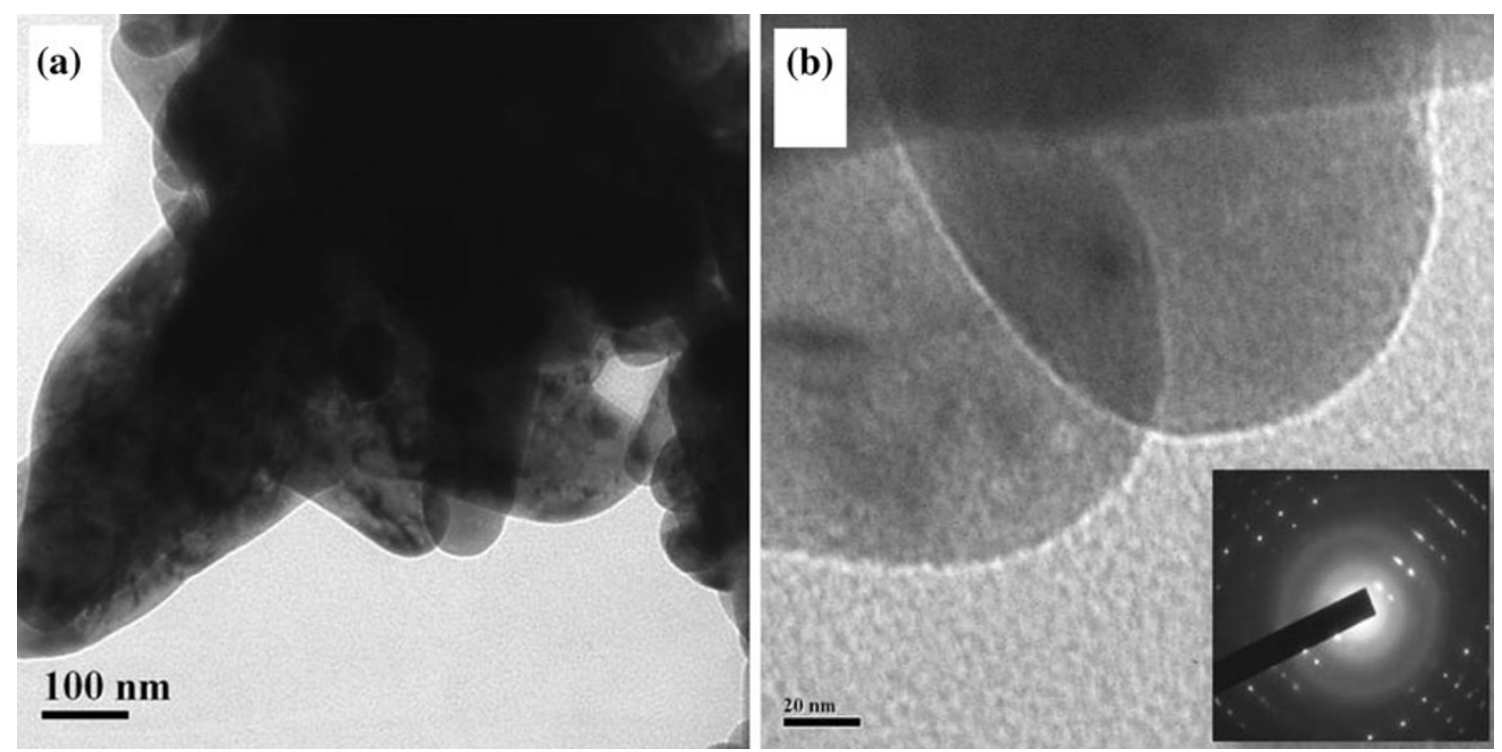

Fig. 4 a, b TEM images of the nanorods annealed at $400^{\circ} \mathrm{C}$. Inset shows the SAED pattern 


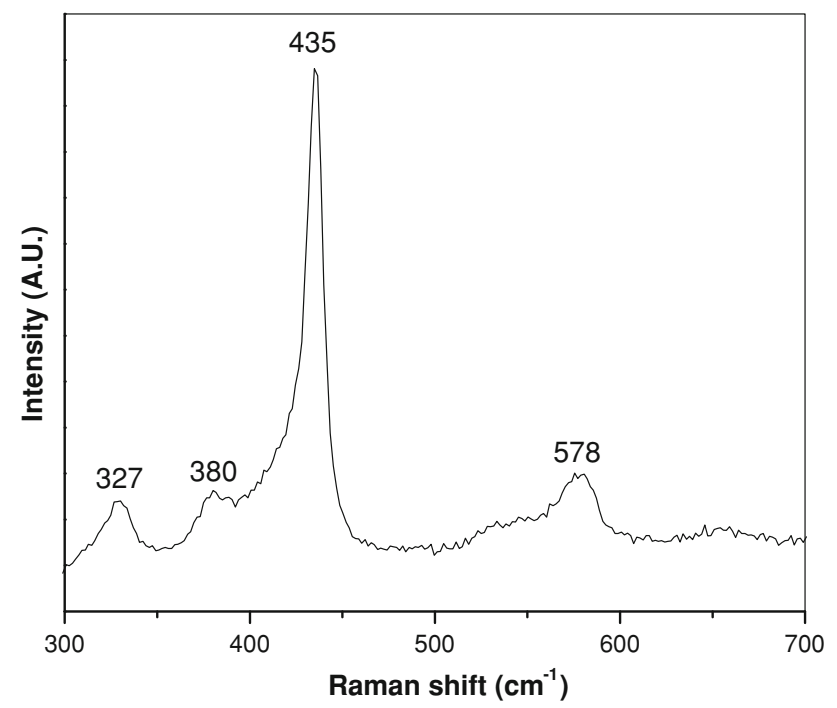

Fig. 6 Raman shift measurements of the nanorods

this case are no longer limited to the Brillouin zone center but dispersed around the centre of the Brillouin zone. This result in the appearance of symmetry forbidden modes along with the shifting and broadening of the first-order optical phonon scattering modes. $\mathrm{ZnO}$ has hexagonal crystal structure with space group $\mathrm{C}_{6 \mathrm{v}}^{4}$. The Raman-active modes for hexagonal $\mathrm{ZnO}$ are $\mathrm{A} 1+2 \mathrm{E} 2+\mathrm{E} 1$. The polar modes A1 and E1 can split into transverse optical (TO) and longitudinal optical (LO) modes. The nonpolar E2 mode is composed of two modes with a low and high frequency. Figure 6 shows the Raman spectra of the $\mathrm{ZnO}$ nanorods. Prominent vibration peaks at $327,380,435$, and $578 \mathrm{~cm}^{-1}$ were observed. The $578 \mathrm{~cm}^{-1}$ peak, positioned between $\mathrm{A}_{1}$ (LO) and $\mathrm{E}_{1}$ (LO) optical phonon mode, arises due to the oxygen deficiency. It is in good agreement with the theoretical calculations of Fonoberov and Balandin (2004). As a result existence of oxygen deficiency, we also observe PL emission peak at $\sim 527 \mathrm{~nm}$. The nonpolar $\mathrm{E}_{2}$ mode is observed at $435 \mathrm{~cm}^{-1}$ (Alim et al. 2005; Samanta et al. 2010). The peak at $381 \mathrm{~cm}^{-1}$ is attributed to $A_{1}$ transverse mode and arises due to the anisotropy in the force constant. It has a different frequency from $\mathrm{E}_{1}$ transverse phonon mode. The $327 \mathrm{~cm}^{-1}$ peak is due to the second order Raman process and is assigned to the $2 \mathrm{E}_{2}$ mode (Fonoberov and Balandin 2004; Alim et al. 2005).

\section{Photoluminescence spectroscopy}

Typical PL spectra of the $\mathrm{ZnO}$ nanorods annealed at different temperatures are shown in Fig. 7. UV emission is the characteristic emission of $\mathrm{ZnO}$ arising due to direct band transition. However, visible emission is also reported from $\mathrm{ZnO}$ nanostructures owing to various defects (Samanta and Chaudhuri 2011; Samanta et al. 2009a, b, c; Vanheusden

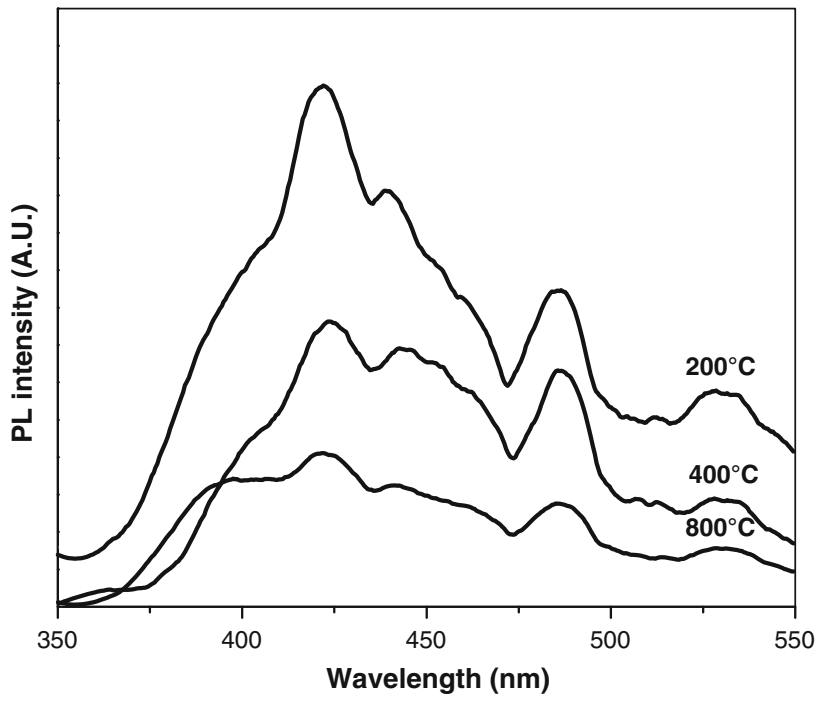

Fig. 7 Room temperature PL spectrum from $\mathrm{ZnO}$ nanorods annealed at different temperatures

et al. 1996; Jeong et al. 2003; Jin et al. 2000; Fu et al. 1998) such as oxygen vacancies, $\mathrm{Zn}$ interstitials, etc. Oxygen, in general, exhibits three types of charge states of oxygen vacancies such as $\mathrm{Vo}^{0}, \mathrm{Vo}^{+}$, and $\mathrm{Vo}^{2+}$. The oxygen vacancies are located below the bottom of the conduction band $(\mathrm{CB})$ in the sequence of $\mathrm{Vo}^{0}, \mathrm{Vo}^{+}$, and $\mathrm{Vo}^{2+}$, from top to bottom. Shallow acceptor levels are created at 0.3 and $0.4 \mathrm{eV}$ above the top of the valence band (VB) due to zinc vacancy $\left(\mathrm{V}_{\mathrm{Zn}}\right)$ and oxygen interstitial $\left(\mathrm{O}_{\mathrm{i}}\right)$, respectively. Again, zinc interstitial $\left(\mathrm{Zn}_{\mathrm{i}}\right)$ produces a shallow donor level at $0.5 \mathrm{eV}$ below the bottom of CB (Samanta and Chaudhuri 2011; Samanta et al. 2009a, b, c; Vanheusden et al. 1996; Jeong et al. 2003; Jin et al. 2000; Fu et al. 1998). In our cases, we observed PL emission (see Fig. 7) in the visible region which indicates that the PL emission from the nanorods in this case is dominated by the defect related deep level emission over the band edge UV emission. Various defect energy levels as calculated from full potential linear Muffin-Tin orbital method (Vanheusden et al. 1996; Jeong et al. 2003; Jin et al. 2000; Fu et al. 1998; Samanta et al. 2009b, c; Lin et al. 2011; Xu et al. 2003) are shown in Fig. 8. The peak at $405 \mathrm{~nm}(3.06 \mathrm{eV})$ corresponds to the transition between conduction band and vacancy zinc level while the peak at $425 \mathrm{~nm}(2.92 \mathrm{eV})$ corresponds to the recombination between electron at zinc interstitials and hole in the valence band (Vanheusden et al. 1996; Jeong et al. 2003; Jin et al. 2000; Fu et al. 1998; Samanta et al. 2009b, c; Lin et al. 2011; Xu et al. 2003). The peak at $485 \mathrm{~nm}(2.55 \mathrm{eV})$ arises due to transition between zinc interstitial and zinc vacancy level. The peak around $527 \mathrm{~nm}$ can be related to singly ionized oxygen vacancy (Vanheusden et al. 1996). This green emission at 


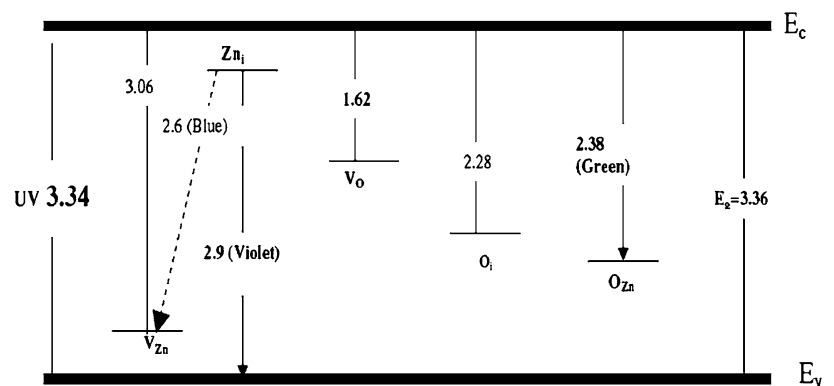

Fig. 8 Defect levels in $\mathrm{ZnO}$

$527 \mathrm{~nm}(2.35 \mathrm{eV})$ is the result of the recombination of a photo-generated hole with a singly ionized charged state of the specific defect. For better understanding of the correlation between PL emission and interstitial $\mathrm{Zn}$, we observed the PL spectra of the samples annealed at 200, 400 and $800^{\circ} \mathrm{C}$, respectively. At high temperature annealing, the small crystallites coalesce together to form large crystallites and the crystallinity of the material improves. This leads to decrease in interstitial zinc states in the nanocrystals resulting less transitions. Hence at higher annealing temperature the intensity of the visible emission peak at $425 \mathrm{~nm}$ from $\mathrm{ZnO}$ nanorods is reduced.

For better understanding of the PL emission mechanism, we studied the low temperature PL spectra of the fabricated $\mathrm{ZnO}$ nanorods over the temperature range of $10-300 \mathrm{~K}$ as shown in Fig. 9. Very sharp peak around $3.36 \mathrm{eV}$ appeared and is assigned to donor-bound excitons $\left(\mathrm{D}^{0} \mathrm{X}\right.$ ) (Mandal et al. 2008; Vaithianathan et al. 2005; Reynolds et al. 2001; Meyer et al. 2004). Another PL peak of very high intensity appeared at $\sim 3.22 \mathrm{eV}$ owing to zero-phonon transition (Mandal et al. 2008; Vaithianathan et al. 2005; Reynolds

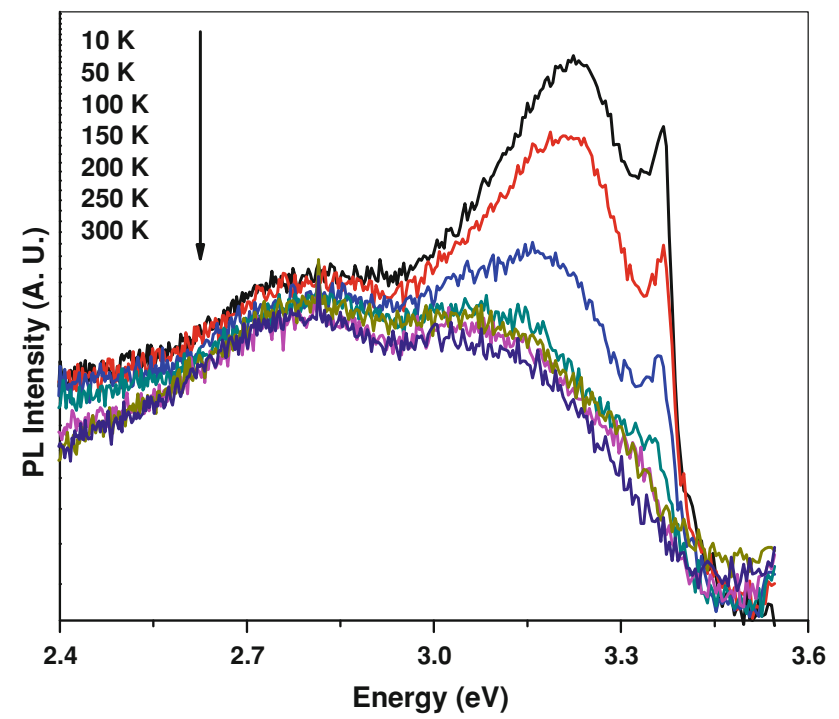

Fig. 9 Low temperature PL spectrum of $\mathrm{ZnO}$ nanorods et al. 2001). However, Meyer et al. (2004) reported that this PL peak is due to donor-acceptor pair transition. It is also reported that the defect-related PL emission dominates for the nanorods of high-aspect ratio as compared to that of bulk because of more number of surface states and incorporation of impurities. However, there are some reports of strong bound excitonic peak at a temperature below $20 \mathrm{~K}$ for $\mathrm{ZnO}$ bulk single crystal (Park et al. 2003). In our case, the room temperature PL is dominated by the defect state emission.

\section{Conclusions}

Hexagonal $\mathrm{ZnO}$ nanorods have been fabricated by a wet chemical process. The fabricated nanorods are well crystallined as revealed from the XRD data. FTIR and Raman shift measurements confirmed various vibrational bonds of the $\mathrm{ZnO}$. A strong violet emission at $425 \mathrm{~nm}$ was observed from the nanorods. This violet emission is very rare finding in $\mathrm{ZnO}$ nanostructures. This violet emission occurs due to the recombination of electrons at zinc interstitials and holes in the valence band. Thus, the fabricated $\mathrm{ZnO}$ nanomaterial can be used as a violet light emitting material and may find its applications in optoelectronic devices.

Acknowledgments The authors sincerely thank Prof. P. R. Chaudhuri and CRF-IIT Kharagpur for providing the FESEM, TEM and FTIR measurements. The authors are also thankful to Prof. S. K. Roy for providing the low temperature PL facility. The authors also acknowledge the financial support provided by Ghatal R. S. Mahavidyalaya to carry out this work.

Open Access This article is distributed under the terms of the Creative Commons Attribution License which permits any use, distribution and reproduction in any medium, provided the original author(s) and source are credited.

\section{References}

Alim KA, Fonoberov VA, Shamsa M, Baladinl AA (2005) MicroRaman investigation of optical phonons in $\mathrm{ZnO}$ nanocrystals. J Appl Phys 97:124313(1)-124313(6)

Duan L, Lin B, Zhang W, Zhong S, Fu Z (2006) Enhancement of ultraviolet emissions from $\mathrm{ZnO}$ films by Ag doping. Appl Phys Lett 88:232110(1)-232113(3)

Faal Hamedani N, Farzaneh F (2006) Islamic Republic of Iran. J Sci 17:231

Fonoberov VA, Balandin AA (2004) Interface and confined optical phonons in wurtzite nanocrystals. Phy Rev B 70:233205(1)233205(4)

Fu ZX, Guo CX, Lin BX, Liao GH (1998) Cathodoluminescence of ZnO Films. Chin Phys Lett 15:457-459

Hu H, Huang X, Deng C, Chen X, Qian Y (2007) Hydrothermal synthesis of $\mathrm{ZnO}$ nanowires and nanobelts on a large scale. Mater Chem Phys 106:58-62 
Iqbal J, Baiqi W, Liu X, Huichao Z, Dapeng Y, Ronghai Y (2009) Role of sp-d exchange interactions in room-temperature photoluminescence and ferromagnetism of $\mathrm{CuCo}$ Co-doped $\mathrm{ZnO}$ nanorods. J Nanosci Nanotechnol 9:6823-6827

Jeong SH, Kim BS, Lee BT (2003) Photoluminescence dependence of $\mathrm{ZnO}$ films grown on $\mathrm{Si}(100)$ by radio-frequency magnetron sputtering on the growth ambient. Appl Phys Lett 82:2625(1)2625(3)

Jin BJ, Im S, Lee SY (2000) Violet and UV luminescence emitted from $\mathrm{ZnO}$ thin films grown on sapphire by pulsed laser deposition. Thin Solid Films 366:107-110

Kale RB, Hsu Y, Lin Y, Lu S (2007) Synthesis of stoichiometric flowerlike $\mathrm{ZnO}$ nanorods with hundred per cent morphological yield. Solid State Commun 142:302-305

Li W, Shi E, Zhong W, Yin Z (1999) Growth mechanism and growth habit of oxide crystals. J Cryst Growth 203:186-196

Li P, Liu H, Zhang Y, Wei Y, Wang X (2007) Synthesis of flowerlike $\mathrm{ZnO}$ microstructures via a simple solution route. Mater Chem Phys 106:63-69

Lin B, Fu Z, Jia Y (2011) Green luminescent center in undoped zinc oxide films deposited on silicon substrates. Appl Phys Lett 79:943(1)-943(3)

Lloyd MT, Lee YJ, Davis RJ, Fang E, Fleming RM, Hsu JWP (2009) Improved efficiency in Poly(3-hexylthiophene)/zinc oxide solar cells via lithium incorporation. J Phys Chem C 113:1760817612

Mandal S, Mullick H, Dhar A, Ray SK (2008) Self-assembled growth of hexagonal $\mathrm{ZnO}$ nanoprisms exhibiting good photoluminescence property. J Electrochem Soc 155:K129-K132

Meyer BK, Alves H, Hofmann DM, Kriegseis W, Forster D, Bertram F, Christen J, Hoffmann A, Strahburg M, Dworzak M, Haboeck U, Rodina AV (2004) Bound exciton and donor-acceptor pair recombinations in ZnO. Phys Status Solidi B Basic Res 241: 231-260

Nian H, Hahn SH, Koo KK, Kim JS, Kim S, Shin EW, Kim EJ (2010) Preparation and characterization of sol-gel $\mathrm{Li}$ and $\mathrm{Al}$ codoped $\mathrm{ZnO}$ thin films. Mater Lett 64:157-160

Pan ZW, Dai ZR, Wang ZL (2001) Nanobelts of semiconducting oxides. Science 291:1947-1949

Park WI, Jun YH, Jung SW, Yi G (2003) Excitonic emissions observed in $\mathrm{ZnO}$ single crystal nanorods. Appl Phys Lett 82:964(1)-964(3)

Patra MK, Manoth M, Singh VK, Gowd GS, Choudhry VS, Vadera SR, Kumar N (2009) Synthesis of stable dispersion of $\mathrm{ZnO}$ quantum dots in aqueous medium showing visible emission from bluish green to yellow. J Lumin 129:320-324

Quang HL, Chua SJ, Loh KP, Zhen C, Thompson CV, Fitzgerald E (2005) The effect of post-annealing treatment on photoluminescence of $\mathrm{ZnO}$ nanorods prepared by hydrothermal synthesis. Adv Mater Micro Nanosyst 1:1-4

Reynolds DC, Look DC, Jogai B, Collins TC (2001) Polariton and free-exciton-like photoluminescence in $\mathrm{ZnO}$. Appl Phys Lett 79:3794(1)-3794(3)

Rout CS, Kulkarni GU, Rao CNR (2009) Electrical and hydrogensensing characteristics of field effect transistors based on nanorods of $\mathrm{ZnO}$ and WO. J Nanosci Nanotechnol 9:5652-5658

Samanta PK, Chaudhuri PR (2011) Growth and optical properties of chemically grown $\mathrm{ZnO}$ nanobelts. Sci Adv Mater 3:107-112
Samanta PK, Patra SK, Chaudhuri PR (2009a) Violet emission from flower-like bundle of $\mathrm{ZnO}$ nanosheets. Physica E 41:664-667

Samanta PK, Patra SK, Chaudhuri PR (2009b) Visible emission from $\mathrm{ZnO}$ nanorods synthesized by a simple wet chemical method. Int J Nanosci Nanotechnol 1:81-90

Samanta PK, Patra SK, Chaudhuri PR (2009c) Green photoluminescence from chemically synthesized $\mathrm{ZnO}$ nanostructure. Int $\mathrm{J}$ Mater Sci 4:803-806

Samanta PK, Bandyopadhyay AK, Basak S, Chaudhuri PR (2010) Characteristics of electrochemically grown dendritic metallic zinc. Int J Light Electron Opt 122:1520-1522

Schilling K, Bradford B, Castelli D, Dufour E, Nash JF, Pape W, Schulte S, Tooley L, Bosch JV, Schellauf F (2010) Human safety review of "nano" titanium dioxide and zinc oxide. Photochem Photobiol Sci 9:495-509

Shan FK, Shin BC, Jang SW, Yu YS (2004) Substrate effects on ZnO thin films prepared by PLD technique. J Eur Ceram Soc 24:1015-1018

Song HS, Zhang WJ, Tang YB, He ZB, Yuan GD, Fan X, Lee CS, Bello I, Lee ST (2010) Field electron emission of $\mathrm{ZnO}$ nanowire pyramidal bundle arrays. J Nanosci Nanotechnol 10:2360-2365

Sugunan A, Warad HC, Boman M, Dutta J (2006) Zinc oxide nanowires in chemical bath on seeded substrates: role of hexamine. J Sol-Gel Sci Technol 39:49-56

Umar A, Park YK, Hahn YB (2009a) High aspect-ratio ZnO nanowires based nanoscale field effect transistors. J Nanosci Nanotechnol 9:2692-2697

Umar A, Rahman MM, Hahn YB (2009b) ZnO nanorods based hydrazine sensors. J Nanosci Nanotechnol 9:4686-4691

Vaithianathan V, Lee BT, Kim SK (2005) Preparation of As-doped $p$-type $\mathrm{ZnO}$ films using a $\mathrm{Zn}_{3} \mathrm{As}_{2} / \mathrm{ZnO}$ target with pulsed laser deposition. Appl Phys Lett 86:062101(1)-062101(3)

Vanheusden K, Seager CH, Warren WL, Tallant DR, Voigt JA (1996) Correlation between photoluminescence and oxygen vacancies in $\mathrm{ZnO}$ phosphors. Appl Phys Lett 68(3):403(1)-403(3)

Wang ZL (2008) Towards self-powered nanosystems: from nanogenerators to nanopiezotronics. Adv Funct Mater 18:3553-3567

Wang XD, Zhou J, Song J, Liu J, Xu N, Wang ZL (2006) Piezoelectric field effect transistor and nanoforce sensor based on a single $\mathrm{ZnO}$ nanowire. Nano Lett 6(12):2768-2772

Wang WS, Wu TT, Chou TH, Chen YY (2009a) A ZnO nanorodbased SAW oscillator system for ultraviolet detection. Nanotechnology 20:135503

Wang M, Cheng X, Yang J (2009b) Controlled visible photoluminescence of $\mathrm{ZnO}$ thin films prepared by RF magnetron sputtering. Appl Phys A Mater Sci Process 96:783-787

Wu X, Bai H, Li C, Shi G (2006) Controlled one-step fabrication of highly oriented $\mathrm{ZnO}$ nanoneedle/nanorods arrays at near room temperature. Chem Commun 15:1655-1657

Xu PS, Sun YM, Shi CS, Xu FQ, Pan HB (2003) The electronic structure and spectral properties of $\mathrm{ZnO}$ and its defects. Nucl Instrum Methods Phys Res Sect B 199:286-290

Zhang J, Sun L, Yin J, Su H, Liao C, Yan C (2002) Control of ZnO morphology via a simple solution route. Chem Mater 14:41724177

Zhang C, Zhang F, Xia T, Kumar N, Hahm J, Liu J, Wang ZL, Xu J (2009) Low-threshold two-photon pumped $\mathrm{ZnO}$ nanowire lasers. Opt Express 17:7893-7900 